\title{
Use of Automatic Safety Belts in Michigan
}

\author{
Fredrick M. Streff and Lisa J. Molnar
}

The use of automatic safety belts among motorists throughout the state of Michigan was examined in May 1990 as part of a broader direct-observation survey to measure compliance with Michigan's mandatory safety belt use law. Use of the two most common types of automatic belt systems were measured: the nonmotorized detachable three-point lap and shoulder belt system and the motorized shoulder belt with manual lap belt system. A total of 828 drivers and 237 front-right passengers were observed with automatic belt systems between April 30, 1990 and May 24, 1990. Use of nonmotorized detachable three-point lap and shoulder belt systems was $74.3 \%$. Lap belt use of motorized shoulder and manual lap belt systems was $79.2 \%$. Of all motorized shoulder belt and manual lap belt systems observed, $97.4 \%$ had the shoulder belts connected.

\section{INTRODUCTION}

Michigan's mandatory safety belt law, implemented in July of 1985 , is one of 34 similar laws in the United States intended to reduce motor-vehicle crash-related deaths and injuries (National Highway Traffic Safety Administration, 1990). Restraint use in Michigan increased sharply from $19.8 \%$ before the law was passed to $58.4 \%$ immediately after it took effect. In December 1985, five months after implementation, restraint

F. M. Streff received his Ph.D. in Applied Psychology from Virginia Polytechnic Institute and State University. He is currently Head of Injury Analysis and Prevention at The University of Michigan Transportation Research Institute.

L. J. Molnar received her M.H.S.A. from the Department of Public Hcalth Policy and Administration, University of Michigan School of Public Health. She is currently a Research Associate with Injury Analysis and Prevention at The University of Michigan Transportation Research Institute. use had declined to $43.0 \%$. It remained at that level until May 1990 when it was observed to be $49.6 \%$ (Streff \& Molnar, 1990).

Because compliance with Michigan's mandatory belt law may be affected by the increasing presence of automatic restraint systems in passenger cars, we examined use of automatic safety belt systems in May 1990. U.S. federal requirements stipulate that automobile manufacturers install automatic restraints (airbags or automatic safety belts) in all 1990 and newer model year cars. The requirement was phased in, beginning with $10 \%$ in $1987,25 \%$ in 1988 , and $40 \%$ in 1989 model ycar cars. Most 1987-1990 cars with automatic restraint systems have automatic safety belts, although airbags are increasingly being used to meet the federal requirement.

Few observational studies of automatic safety belt use have been conducted, but findings indicate that use rates of automatic belt systems are considerably higher than manual systems, although rates vary across types of 
automatic belt systems. Williams, Wells, Lund, and Teed (1989) observed use of automatic belt systems supplied by Ford and Toyota (motorized nondetachable automatic shoulder belt), Nissan (motorized detachable shoulder belt), Volkswagen and Chrysler (nonmotorized detachable shoulder belt), and General Motors (nonmotorized detachable three-point lap and shoulder belt) in 1987. The authors found use of automatic belts to be higher than manual belts in otherwise comparable late-model cars for all manufacturers except Chrysler. Automatic shoulder belts in Ford, Toyota, Nissan, and Volkswagen cars increased belt use rates to around $90 \%$. Lap belt use was highest in General Motors cars. For other manufacturers, manual lap belt use was about half that of automatic shoulder belt use. However, these other automatic belt systems also provided knee bolsters to supplement shoulder belt protection.

In an update of their 1987 survey, Williams, Wells, Lund, and Teed (1990) observed safety belt use in 1986-1990 model year cars in suburban Washington D.C., Chicago, Los Angeles, and Philadelphia. They found driver shoulder belt use in cars with automatic twopoint systems to be substantially higher than in the same model cars with manual threepoint belts, although use rates varied depending on the type of automatic shoulder belt system. Shoulder and lap belt use was slightly higher in General Motors cars with nonmotorized detachable threc-point lap and shoulder belts compared to the same model cars with manual three-point belts; in other cars with automatic three-point belts there was no difference in manual three-point belt rates and automatic three-point belt use rates. Observed automatic belt use rates were as follows: motorized nondetachable shoulder belts, $92 \%$; motorized detachable shoulder belts, $83 \%$; nonmotorized detachable shoulder belts, $75 \%$; and nonmotorized detachable three-point lap and shoulder belts, $66 \%$. The authors found lap belt use with automatic shoulder belts to be lower than manual three-point belts in the same model cars but were not able to reliably estimate precisely how much lower.

Bowman and Rounds (1989) observed belt use in 19 U.S. cities in 1988 and found overall automatic belt use of drivers to be $88.1 \%$, compared to $56.1 \%$ for 1987-89 model year 142 cars with manual safety belts. Use was highest for motorized nondetachable shoulder belt systems (98.3\%). Automatic belt use was lowest for nonmotorized detachable three-point lap and shoulder belt systems $(76.6 \%)$. Use rates for motorized detachable shoulder belt systems and nonmotorized shoulder belt systems were $92.1 \%$ and $80.2 \%$, respectively. While the authors presented use rates by manufacturer, they cautioned that in many cases the numbers of observations were too small for reliable estimates. Lap belt use with automatic shoulder belt systems was not reported.

Follow-up observations of belt use in the same 19 U.S. cities in 1989 indicated that automatic belt use of drivers was $84.8 \%$, compared to $54.9 \%$ for $1987-90$ model year cars with manual safety belts (Datta \& Guzek, 1990). Automatic belt use remained highest for motorized nondetachable shoulder belt systems $(97.9 \%)$. Use rates for other types of automatic belt systems were as follows: motorized detachable shoulder belts, 88.7\%; nonmotorized detachable three-point systems, $74.7 \%$; and nonmotorized shoulder belt systems, $71.6 \%$.

Reinfurt, St. Cyr, and Hunter (1990) examined driver safety belt use in late model cars in North Carolina. Overall use of automatic belts independent of system type was $79.6 \%$ compared to $76.3 \%$ for manual threepoint systems. Among drivers with motorized shoulder belt systems with manual lap belts, shoulder belt use was $94.2 \%$; however, only $28.6 \%$ of drivers with these systems were observed using their lap belts. Automatic belt use was lowest among drivers with nonmotorized three-point lap and shoulder belt systems (76.9\%).

We examined use of automatic safety belts among motorists throughout Michigan in May of 1990 as part of a broader series of directobservation surveys to measure compliance with Michigan's mandatory safety belt use law. Thirteen surveys of safety belt use among motor-vehicle occupants throughout Michigan have been conducted in this series (December 1984; April, July, and December 1985; April, July, and December 1986; April, July, and November 1987; May 1988; April 1989; and May 1990). In May 1990, we also measured use of the two most common types of automatic belt systems: the nonmotorized detach- 
able three-point lap and shoulder belt system and the motorized shoulder belt and manual lap belt system.

\section{METHODS}

Trained field observers examined use of automatic safety belts by drivers and frontright passengers of cars throughout Michigan as part of a broader direct-observation study of safety belt use. Because overall rates of belt use vary greatly depending on location, a carefully designed set of observation sites was used to sample motorists traveling during daylight hours on Michigan roads. The goal was to minimize total survey error, including sampling error and measurement error, while using sites where observations could be made efficiently and economically. To observe all modes of restraint use among occupants of motor vehicles - not just shoulder belt use vehicles had to be motionless for at least several seconds. As a result, observation sites were generally limited to intersections with three-color cycling traffic signals. Observations were limited to daylight hours for accurate observation of restraint use and were distributed carefully across hours of the day and days of the week.

A total of 240 intersections was selected with the use of a multistage stratified probability sampling procedure. To provide sufficient cases for regional-specific analyses, the upper peninsula regions were overrepresented in the sample in relation to their populations, and the densely populated southeastern region of the state was underrepresented. Therefore, all results are reweighted according to the sampling fraction used in each region. Within each region, counties were selected so that the largest counties had the highest probability of inclusion in the sample; that is, counties were selected with a probability proportional to their size. Some counties were selected more than once because of their large populations. Within each county, intersections were selected randomly from lists of possible intersections.

Trained field staff visited each sampled intersection and observed a sample of about 50 vehicles during a pre-selected 45-minute period. Within each sampling area, the first site observed for each day and city was select- ed using a random number table, with the remaining sites observed in an order determined by proximity, to minimize the amount of travel time required between sites. Observers limited the number of vehicles recorded during any given traffic signal cycle to three to prevent inclusion of motorists who might have buckled up after noticing the observer examine vehicles ahead of them in the traffic queue.

Observers were trained to recognize and record information for the two most common types of automatic belt systems: the nonmotorized detachable three-point lap and shoulder belt system, and the motorized shoulder belt with manual lap belt. Inter-observer reliability data were collected during training. Inter-observer reliability for safety belt observations exceeded $90 \%$ before field observations began. We focused our observations of automatic belt use on general types of systems rather than specific automobile manufacturers supplying the systems because we expected only a small portion of all vehicles observed to have automatic belt systems due to the recency of automatic restraint system mandates. Observers recorded on pre-coded forms whether nonmotorized detachable three-point lap and shoulder belt systems were attached or not attached and whether lap belts of motorized shoulder belt and manual lap belt systems were attached or not attached. Observers also noted cases in which motorized shoulder belts had been disconnected. Additional information on overall restraint use (including manual and automatic belt systems and child restraint systems), seating position, estimated age, and gender for occupants in each sampled vehicle was collected as part of the broader survey of restraint use among motorists throughout the state. Further detail on the sample design, data collection procedures, and analytic procedures used throughout the series of direct-observation surveys can be found in Wagenaar and Wiviott (1985).

In calculating overall restraint use rates in the broader direct-observation survey, occupants observed with a motorized shoulder belt system in which the lap belt was not attached were considered unbelted even if the motorized shoulder belt was used. This was done because we consider the lap belt to be an important part of the overall system even 
though knee bolsters are also provided. Because relatively few motorized shoulder belt with manual lap belt systems were observed compared to all restraint systems, designating these cases as unbelted had an insignificant effect on overall use rates.

\section{RESULTS}

A total of 11,705 cars and light trucks was observed between April 30, 1990 and May 24, 1990. Automatic safety belt data were collected for 828 drivers and 237 front-right passengers in these vehicles. Information on use of automatic safety belts is presented in Table 1 . Belt use among drivers and front-right occupants of cars with nonmotorized detachable three-point lap and shoulder belt systems was $74.3 \%$ overall. Use of lap belts among drivers and front-right occupants of cars with motorized shoulder belt and manual lap belt systems was $79.2 \%$ overall. Of all motorized shoulder belt and manual lap belt systems observed, $97.4 \%$ had the shoulder belts connected.

Because the nonmotorized three-point lap and shoulder belt system is detachable, it is not possible to determine how many belt users were employing the system in the automatic mode and how many were using it as a manual belt. In a telephone survey of owners of cars with this type of automatic belt, Williams, Wells, and Lund (1987), found almost half of the respondents reported not knowing that the belts in their cars were automatic systems. Surveys of cars with automatic belts parked at office parking lots and shopping malls in Maryland and Virginia suburbs of Washington, D.C., conducted in 1987 and 1989 found that only about $1 \%$ of driver nonmotorized detachable three-point lap and shoulder belts were connected (Williams, Wells, Lund, \& Teed, 1987, 1990).

In a follow-up survey to our automatic safety belt observations, we examined cars parked in office parking lots and shopping malls in southeastern Michigan and found that only $1.4 \%$ of nonmotorized detachable three-point lap and shoulder belts were connected $(1.7 \%$ of driver belts and $1.1 \%$ of passenger belts; see Table 2). By comparison, $100 \%$ of motorized nondetachable shoulder belts were connected, $94.7 \%$ of motorized detachable shoulder belts were connected, and $50 \%$ of nonmotorized detachable shoulder belts were connected.

\section{DISCUSSION}

Findings reported here indicate that use rates of automatic belt systems by motorists in Michigan are considerably higher than overall restraint use. In May 1990, over three-quarters of motorists observed with automatic belts were using their belts. By comparison, about half of all motorists were observed to be restrained during the same period. While the appearance of automatic safety belt systems in cars has had a positive effect on belt use, considerable numbers of motorists are still traveling without the full protection afforded by automatic belt systems. For example, we found that over $20 \%$ of drivers and front-right passengers were not benefitting fully from their automatic shoulder belt with manual lap

TABLE 1

AUTOMATIC BELT USE BY TYPE OF BELT SYSTEM AND SEATING POSITION

\begin{tabular}{|c|c|c|c|}
\hline \multirow{2}{*}{ Type of Belt System } & \multicolumn{3}{|c|}{ Seoting Position } \\
\hline & Driver & Front Right & All \\
\hline $\begin{array}{l}\text { Nonmotorized three-point lap and shol skder belt } \\
\text { \% attoched } \\
\text { unweighted } N\end{array}$ & $\begin{array}{r}75.3 \\
611\end{array}$ & $\begin{array}{r}70.7 \\
173 \\
\end{array}$ & $\begin{array}{r}74.3 \\
784\end{array}$ \\
\hline $\begin{array}{l}\text { Motorized shoukder belt with manual kap belt } \\
\text { \% kap belt attached } \\
\text { unweighted } N\end{array}$ & $\begin{array}{r}79.4 \\
217\end{array}$ & $\begin{array}{r}78.3 \\
64\end{array}$ & $\begin{array}{r}79.2 \\
281\end{array}$ \\
\hline
\end{tabular}


TABLE 2

PERCENT OF AUTOMATIC BELTS CONNECTED IN PARKED CARS BY TYPE OF BELT SYSTEM AND SEATING POSITION

\begin{tabular}{|c|c|c|c|}
\hline \multirow{2}{*}{ Type of Belt System } & \multicolumn{3}{|c|}{ Seating Position } \\
\hline & Driver & Front Right & All \\
\hline $\begin{array}{l}\text { Nonmotorized three-point lap and shoulder belt } \\
\% \text { connected } \\
\text { Number Obsened }\end{array}$ & $\begin{array}{r}1.7 \\
180\end{array}$ & $\begin{array}{r}1.1 \\
178^{1}\end{array}$ & $\begin{array}{r}1.4 \\
358\end{array}$ \\
\hline $\begin{array}{l}\text { Motorized nondetachable shoulder belt } \\
\text { \% connected } \\
\text { Number Observed }\end{array}$ & $\begin{array}{r}100.0 \\
129\end{array}$ & $\begin{array}{r}100.0 \\
129\end{array}$ & $\begin{array}{r}100.0 \\
258\end{array}$ \\
\hline $\begin{array}{l}\text { Motorized detochable shoulder belt } \\
\text { \% connected } \\
\text { Number Obsened }\end{array}$ & $\begin{array}{r}95.3 \\
85\end{array}$ & $\begin{array}{r}94.1 \\
85\end{array}$ & $\begin{array}{r}94.7 \\
170\end{array}$ \\
\hline $\begin{array}{l}\text { Nonmotorized detachable shoulder belt } \\
\text { \% connected } \\
\text { Number Observed }\end{array}$ & $\begin{array}{r}50.0 \\
10\end{array}$ & $\begin{array}{r}50.0 \\
10\end{array}$ & $\begin{array}{r}50.0 \\
20\end{array}$ \\
\hline
\end{tabular}

'In two cases, child restraint devices were observed in the front-right possenger seats. Because information on whether the nonmotorized detachable thre日-point lap and shoulder belts were connected was not relevant in these cases, these cars were not included in the "connected" percentage.

belt systems because they failed to use the manual lap belts. Other studies found rates of lap belt use to be much lower, with observed levels as low as 28\% (Reinfurt et al., 1990). Our automatic belt observations were part of a broader study to measure overall restraint use among motorists; the study was not designed to solely measure automatic belt use. Further research is needed to determine if differences across studies in manual lap belt use with automatic shoulder belt systems are due to observation strategies or other factors.

Another focus for further research is the effect of airbag availability on safety belt use. Airbags are increasingly being used to meet federal requirements for automatic restraint systems. There has been some concern that motorists in cars with airbags may be less likely to use safety belts because they believe that airbags alone provide sufficient crash protection. Williams et al. (1990) found no evidence of this in a survey of belt use in late model cars with and without airbags in four metropolitan areas. Overall, $66 \%$ of drivers in cars with airbags were observed using their safety belts compared to $63 \%$ of drivers in cars without airbags using their safety belts. Comparisons by metropolitan area, model year, manufacturer, and car size resulted in very small or no differences in driver belt use in cars with and without airbags. Datta and Fall 1991/Volume 22/Number 3
Guzek (1990) also found belt use rates for drivers of cars with and without airbags in 19 U.S. cities to be similar ( $58 \%$ versus $52.8 \%$ ). Reinfurt et al. (1990) compared belt use rates for automatic belt systems, and manual threepoint systems with and without airbags. Use of manual three-point belts in cars with airbags was slightly lower than belt use in cars without airbags $(73.9 \%$ versus $76.3 \%)$. It is important to continue to monitor belt use in cars with airbags as use of airbags becomes increasingly widespread.

Finally, continuing efforts to assess effects of automatic belt use on compliance with mandatory belt use laws are worthwhile. The overall restraint use rate observed in May 1990 in Michigan (49.6\%) represented the first significant increase in restraint use since July 1985, immediately after Michigan's mandatory belt use law took effect. Although this increase may have been due in large part to the increasing availability of automatic belt systems in passenger cars, this was found not to be the case. We examined restraint use excluding vehicles with automatic belt systems from our analyses and found restraint use to be $47.8 \%$. This figure is not significantly lower than the $49.6 \%$ use rate overall. However, as cars with automatic belt systems increasingly make up a larger share of all cars on the road, we expect use of automatic belts 
to have an increasingly larger effect on overall restraint use rates.

\section{ACKNOWLEDGEMENTS}

We express our appreciation to several individuals who were essential to the completion of this project. Johannes deLange, Francis Nwachukwu, and Hans Thoma conducted field observations. Carl Christoff supervised data collection. Robert Schultz assisted with data file management and analyses, and Laura Ratzlaff assisted with report production.

The research reported here was supported in part by the Michigan Office of Highway Safety Planning and the U.S. Department of Transportation, National Highway Traffic Safety Administration. Findings and conclusions are solely the authors'.

\section{REFERENCES}

Bowman, B. L., \& Rounds, D. A. (1989). Restraint system usage in the traffic population 1988 annual report. Washington, D.C.: National Highway Traffic Safety Administration.
Datta, T. K., \& Guzek, P. (1990). Restraint system use in 19 U.S. cities 1989 annual report. Washington D.C.: U.S. Department Transportation, National Highway Traffic Safety Administration.

National Highway Traffic Safety Administration (1990). Idea sampler: belts and bags - a winning combination. Washington, D.C.: U.S. Department of Transportation.

Reinfurt, D. W., St. Cyr, C. L., \& Hunter, W. W. (1990, October). Usage patterns and misuse rates of automatic seat belts by system type. Paper presented at American Association for Automotive Medicine 34th Annual Conference, Scottsdale, A7.

Streff, F. M., \& Molnar, L. J. (1990). Direct observation of safety belt use in Michigan: Spring 1990. Ann Arbor, MI: The University of Michigan Transportation Research Institute.

Wagenaar, A. C., \& Wiviott, M. B. T. (1985). Direct Observation of seat belt use in Michigan: December 1984. Ann Arbor, MI: The University of Michigan Transportation Research Institute.

Williams, A. F., Wells, J. K., \& Lund, A. K. (1990). Seat belt use in cars with airbags. American Journal of Public Health, 80(12), 1514-1516.

Williams, A. F., Wells, J. K., \& Lund, A. K. (1987). Driver use of, and reaction to, automatic seat belts in Ford and $G M$ cars. Washington, D.C.: Insurance Institute for Highway Safety.

Williams, A. F., Wells, J. K., Lund, A. K., \& Teed, N. J. (1989). Observed use of automatic seat belts in 1987 cars. Accident Analysis and Prevention, 21(5), 427-433.

Williams, A. F., Wells, J. K., Lund, A. K., \& Teed, N. J. (1990). Seat belt use in cars with automatic belts. Manuscript submitted for publication. 